University of Wollongong

Research Online

Faculty of Informatics - Papers (Archive)

Faculty of Engineering and Information

Sciences

$1-1-2005$

\title{
Assessing the Impact of Increased Air Conditioner Load on Power Quality in Australia
}

Lianne Mollier

D A. Robinson

University of Wollongong, duane@uow.edu.au

Sarath Perera

University of Wollongong, sarath@uow.edu.au

Victor J. Gosbell

University of Wollongong, vgosbell@uow.edu.au

Frank Bucca

Follow this and additional works at: https://ro.uow.edu.au/infopapers

Part of the Physical Sciences and Mathematics Commons

\section{Recommended Citation}

Mollier, Lianne; Robinson, D A.; Perera, Sarath; Gosbell, Victor J.; and Bucca, Frank: Assessing the Impact of Increased Air Conditioner Load on Power Quality in Australia 2005.

https://ro.uow.edu.au/infopapers/1216

Research Online is the open access institutional repository for the University of Wollongong. For further information contact the UOW Library: research-pubs@uow.edu.au 


\title{
Assessing the Impact of Increased Air Conditioner Load on Power Quality in Australia
}

\author{
Abstract \\ Measurements of performance of existing technology air conditioner systems with regards to their \\ impact on power quality in LV distribution systems are presented. Three types of split-phase air \\ conditioners are studied including direct on line starting, soft starter and inverter fed units. Results of \\ testing and subsequent calculations illustrate that the direct on line and soft starter units do not meet \\ compliance requirements of the relevant standard, and as penetration of air conditioners increases, \\ voltage fluctuations may become a significant problem in some LV distribution systems in Australia.

\section{Keywords} \\ quality, power, load, conditioner, air, increased, impact, australia, assessing

\section{Disciplines} \\ Physical Sciences and Mathematics

\section{Publication Details} \\ Mollier, L., Robinson, D. A., Perera, S., Gosbell, V. J. \& Bucca, F. (2005). Assessing the Impact of Increased \\ Air Conditioner Load on Power Quality in Australia. In G. George (Eds.), 18th International Conference and \\ Exhibition on Electricity Distribution Italy: CIRED International Conference on Electricity Distribution.
}




\title{
ASSESSING THE IMPACT OF INCREASED AIR CONDITIONER LOAD ON POWER QUALITY IN AUSTRALIA
}

\author{
Lianne MOLLER*, Duane ROBINSON*, Sarath PERERA*, Vic GOSBELL*, Frank BUCCA $\dagger$ \\ *Integral Energy Power Quality and Reliability Centre, University of Wollongong - Australia \\ $\dagger$ Integral Energy, Huntingwood - Australia \\ duane@uow.edu.au
}

\begin{abstract}
SUMMARY
Measurements of performance of existing technology air conditioner systems with regards to their impact on power quality in LV distribution systems are presented. Three types of split-phase air conditioners are studied including direct on line starting, soft starter and inverter fed units. Results of testing and subsequent calculations illustrate that the direct on line and soft starter units do not meet compliance requirements of the relevant standard, and as penetration of air conditioners increases, voltage fluctuations may become a significant problem in some LV distribution systems in Australia.
\end{abstract}

\section{INTRODUCTION}

Air conditioner load on electrical distribution systems has seen a dramatic increase over the past five years with the installation of large single-phase split-systems becoming commonplace in most modern Australian households. With increasing penetration of air conditioners, it is important for Distribution Network Service Providers (DNSP) to have an understanding of this major load type and its impact on network operation. The larger air conditioner units of concern are currently available in ratings from $6.5 \mathrm{~kW}$ to $8.5 \mathrm{~kW}$. The steadily increasing rating and number of installations of these air conditioner units has the potential to produce both peak demand and power quality related problems for DNSPs.

Consequently, residential air conditioner load is now a significant part of the summer peak demand in Australian distribution systems. Investigations by Integral Energy, a DNSP in the state of New South Wales incorporating Sydney and surrounding areas, indicate that residential air conditioner load contributes over $50 \%$ of the load in some of their substations and is already creating many demand related problems during summer periods.

Figures from the Australian Bureau of Statistics (ABS) suggest an air conditioner penetration rate of approximately 44\% in 2002 for households in the state of New South Wales [1]. For Integral Energy, network wide penetration levels of air conditioners stand at $62 \%$, with recently developed areas such as Western Sydney having a penetration level of $74 \%$ [2]. In new release areas anecdotal evidence indicates air conditioner penetration may be as high as $80 \%$. In addition, a number of areas of Australia have seen new housing being constructed with less efficient designs with regards to cooling. As a result, this has contributed to commercially available air conditioner units steadily increasing in rating.
Whilst reported demand related issues are considerable [3, 4], there is growing concern on the effect of air conditioner load on power quality. Power quality problems arising from the use of air conditioners include; voltage sags during starting, steady state voltage drop, harmonics from the induction motors operating in their region of saturation and also from the use of front end power electronics, and voltage fluctuations due to the combined effects of the starting of a number of units sharing the same LV distributor. Starting characteristics of air conditioners have the largest impact on power quality due to voltage drops arising from significant locked rotor currents drawn by the induction machines driving the compressor.

The Integral Energy Power Quality and Reliability Centre at the University of Wollongong recently undertook measurements, on the behalf of Integral Energy, of the power quality disturbances created by typical large capacity singlephase split-system air conditioner units [5]. The results of the measurements have been used to determine compliance of the units in accordance with the relevant power quality standards and also as a basis to complete calculations of the overall impact of the growing penetration of such systems in Integral Energy's distribution network from a power quality viewpoint.

\section{AIR CONDITIONER UNITS UNDER TEST}

Starting and steady state characteristics for three types of air conditioners were measured under laboratory conditions. The three types of units were identified by their starting techniques; direct on line (DOL), soft starter, and inverter fed units. A popular manufacturer in Australia provided two air conditioner test units via an agreement with Integral Energy. The units provided were as follows:

(i) Soft starter air conditioner unit

A $240 \mathrm{~V}$ split-system providing $8.0 \mathrm{~kW}$ of rated cooling power with a full load current of 13.5A. The unit utilises a single-phase capacitor-start motor to drive the compressor, and was also reconfigured during testing (electronic soft starter removed) to allow DOL tests.

(ii) Inverter fed air conditioner unit

A $240 \mathrm{~V}$ split-system providing $8.0 \mathrm{~kW}$ of rated cooling power with a full load current of 13.8A. The unit utilises a three-phase motor supplied by a single-phase to threephase inverter to drive the compressor.

For each of the units a standard supply and input impedance was used to obtain measurements in the laboratory that allow quantification of the impact on power quality during starting 
transients and steady state. Results of the tests are presented in Section 4.

\section{RELEVANT POWER QUALITY STANDARDS}

Calculations for comparison with the requirements of the relevant IEC 61000 series power quality standards (adopted in Australia the AS/NZS 61000 series) were performed during the testing of the air conditioner units. The standards for harmonic emissions and voltage changes based on the air conditioner ratings are AS/NZS 61000.3.2 [6] and AS/NZS 61000.3.3 [7] respectively.

AS/NZS 61000.3.2 specifies the limits for harmonic emissions for equipment with rated current less than or equal to $16 \mathrm{~A}$. Assuming the air conditioners units under test fall within the Class A specification of the standard, emissions limits are based on acceptable magnitudes of harmonic currents as provided in Table I.

AS/NZS 61000.3.3 specifies the limits for voltage changes, fluctuations and flicker in low voltage supply systems. This standard is also designed for equipment with rated current less than or equal to 16A. According to an earlier version of the standard the maximum relative voltage change created by air conditioner starting currents should not exceed $4 \%$ when connected to a $230 \mathrm{~V}$ supply with standard test impedance of $0.40+\mathrm{j} 0.25 \Omega$ (including neutral). Revisions of the standard in 2003 included an increase in the maximum allowable relative voltage change from $4 \%$ to $6 \%$ for equipment with delayed restart, which includes the air conditioner units under test.

\section{LABORATORY TESTS PERFORMED}

The two air conditioner units tested both operate from a single-phase $240 \mathrm{~V} 50 \mathrm{~Hz}$ supply. Voltage and current probes from a high speed oscilloscope were coupled to the supply lines at the point connection to the units to capture the raw voltage and current waveforms during transient and steady state conditions. To enable soft starter and DOL tests the soft starter incorporated in the first unit was bypassed and the starting capacitance adjusted appropriately. The temperature control of the units was adjusted to a minimum temperature level of $18^{\circ} \mathrm{C}$ in order to create the maximum load.

\begin{tabular}{|} 
TABLE I - Limits for class A equipment [6] \\
\begin{tabular}{|c|c|}
\hline $\begin{array}{c}\text { Harmonic order } \\
\mathrm{N}\end{array}$ & $\begin{array}{c}\text { Maximum } \\
\text { permissible harmonic } \\
\text { current (A) }\end{array}$ \\
\hline \multicolumn{2}{|c|}{ Odd harmonic } \\
\hline 3 & 2.30 \\
5 & 1.14 \\
7 & 0.77 \\
9 & 0.40 \\
11 & 0.33 \\
13 & 0.21 \\
$15 \leq \mathrm{n} \leq 39$ & $0.15 \times 15 / \mathrm{n}$ \\
\hline \multicolumn{2}{|c|}{ Even harmonics } \\
\hline 2 & 1.08 \\
6 & 0.43 \\
$8 \leq \mathrm{n} \leq 40$ & 0.30 \\
\hline
\end{tabular}
\end{tabular}

\subsection{Starting Transients}

Starting of the air conditioner units is defined as the moment the compressor motor is energised. This occurs after a slight delay from when the unit is first turned on, and only when the room temperature is above that of the threshold temperature set in the control unit.

Steady state, starting transients, and reduced voltage operation were all incorporated into the laboratory tests. Harmonic emissions were calculated form the steady state current waveforms. The source impedance of the laboratory supply was estimated to be $0.11+\mathrm{j} 0.04 \Omega$. Reduced voltage testes were achieved through the use of a single-phase variac that inherently increases the supply impedance to $0.46+\mathrm{j} 0.19 \Omega$, close to that required by the AS/NZS 61000.3 .3 standard. Calculation of all rms values and power quality indices was completed using raw voltage and current waveforms and a half cycle sliding window.

Typical starting voltage and current waveforms and rms values obtained during starting of the soft starter air conditioner unit are illustrated in Fig. 1 to Fig. 3. As shown, a significant starting current and resulting voltage drop occur.

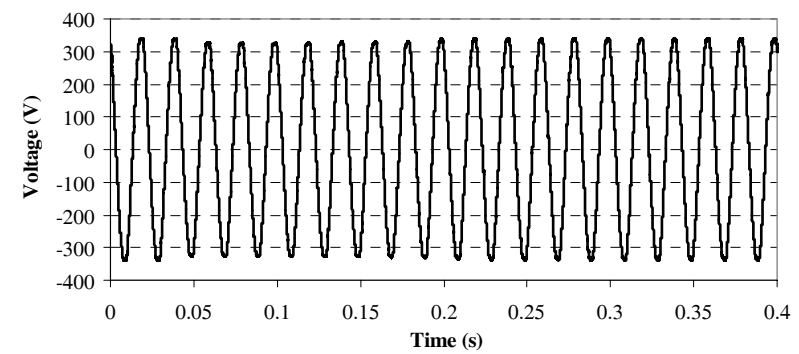

Fig. 1 - Typical starting voltage waveform for soft starter air conditioner unit

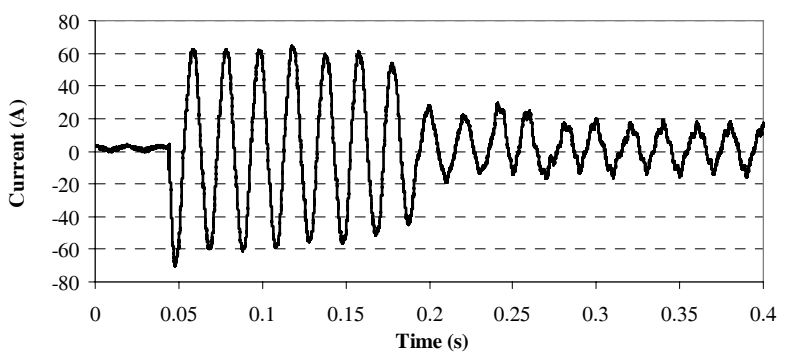

Fig. 2 - Typical starting current waveform for soft starter air conditioner unit

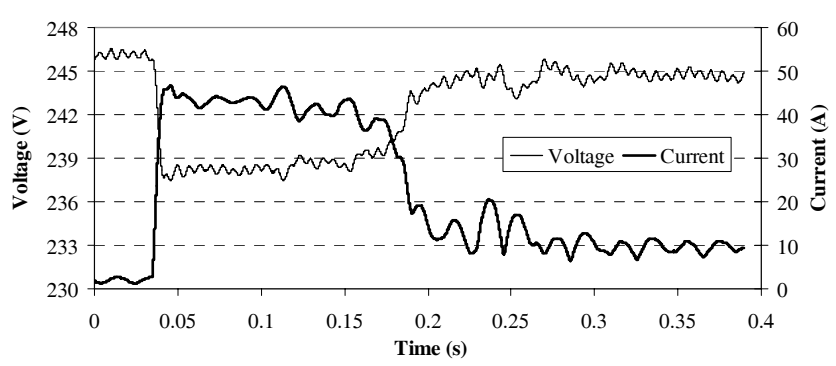

Fig. 3 - Calculated rms current and voltage for soft starter air conditioner unit 
During the starting phase of the soft starter air conditioner unit the current and voltage are in phase, i.e. zero displacement angle. This increases the real power delivered to the motor, as a result reducing the starting current as compared to DOL starting. The displacement angle after the starting phase increases to $23^{\circ}$ once the motor has reached threshold speed of $75 \%$ of rated, at which time the controller bypasses the soft starter electronics. The peak current during starting was recorded to be $72.4 \mathrm{~A}$. The voltage drop experienced in the laboratory during the starting phase was $2.1 \%$. Given that the source impedance of the laboratory is approximately a quarter of the test impedance specified in the AS/NZS 61000.3.3 standard, it is likely that the recommended limit of $6 \%$ voltage drop would be exceeded with the soft starter in operation.

With the soft starter air conditioner unit reconfigured to start DOL the starting transients measurements were again undertaken. Fig. 4 and Fig. 5 illustrate a typical current waveform and rms voltages and currents for the DOL configured unit during starting. It is noted that the starting phase duration of the DOL configuration is slightly shorter than that of the soft starter unit. As expected the peak current is approximately double that of the soft starter unit at $152 \mathrm{~A}$. The displacement angle between the current and voltage waveform for the DOL unit is consistent at $23^{\circ}$ during starting and at steady state.

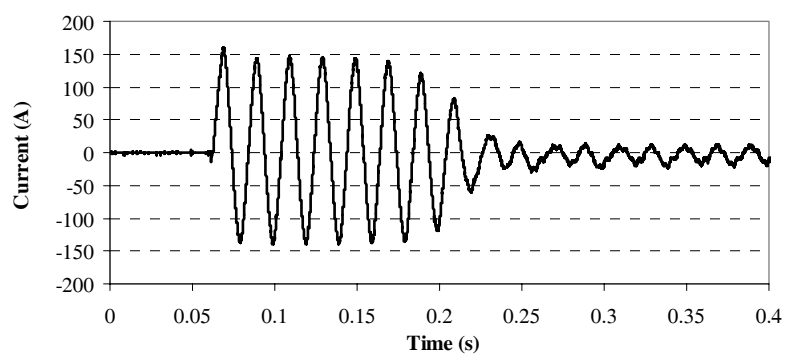

Fig. 4 - Typical starting current waveform for DOL air conditioner unit

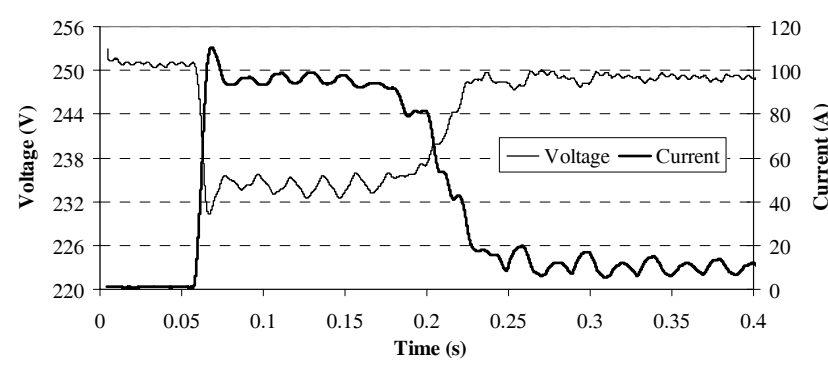

Fig. 5 - Calculated rms current and voltage for DOL air conditioner unit

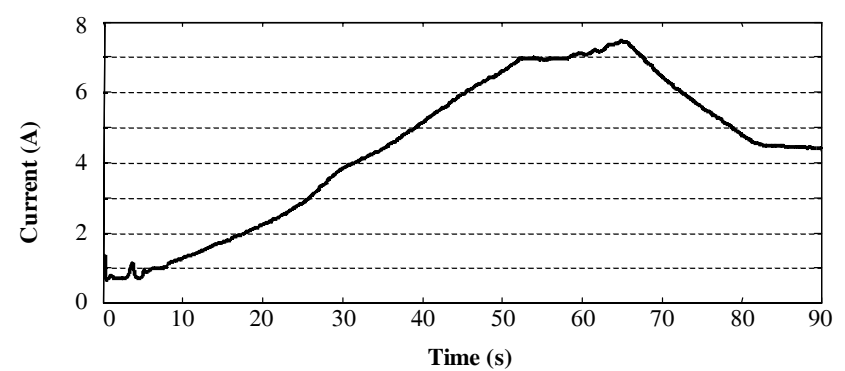

Fig. 6-Calculated rms current for inverter fed air conditioner unit
The voltage sag experienced during the starting of the DOL configuration is approximately $4.6 \%$, ensuring that if the unit was connected to the test impedance recommended in AS/NZS 61000.3.3 it would not meet requirements.

The inverter fed unit was also studied during start up. However, as the unit incorporates a variable speed drive the unit is slowly brought up to maximum speed and thus does not illustrate the starting transient effects of the DOL configuration and soft starter units. Fig. 6 illustrates the rms current during starting of the inverter fed unit, noting that time to reach full speed is approximately 80 seconds.

The maximum rms current of the inverter fed unit during starting was 7.3A. From nominal speed the inverter either increases or decreases the speed of the motor to adjust air conditioner cooling as required, operating the compressor constantly. The inverter operates with unity displacement power factor.

\subsection{Steady State Operation}

Steady state operation of the DOL configuration and soft starter unit are identical, as the air conditioner controller bypasses the soft starter, connecting directly to the mains, after the compressor motor has reached the threshold speed. During steady state operation of the air conditioners the laboratory supply voltage waveform contained no significant additional harmonics with the air conditioner units operating. The steady state fundamental voltage drop was approximately $0.7 \%$ below nominal. The dominant harmonic currents drawn by the compressor motor include the $3^{\text {rd }}$ and $5^{\text {th }}$ harmonic as indicated in Table II. A large component of the harmonic current can be attributed to the motor construction and resulting saturation typical of single-phase machines with limitations on size and weight.

Table II - Harmonic current emissions for the soft starter air conditioner unit

\begin{tabular}{|c|c|c|}
\hline $\begin{array}{c}\text { Harmonic number } \\
\mathrm{n}\end{array}$ & $\begin{array}{c}\text { Voltage harmonics } \\
\text { as \% of } \\
\text { fundamental }\end{array}$ & $\begin{array}{c}\text { Current harmonics } \\
\text { as \% of } \\
\text { fundamental }\end{array}$ \\
\hline 2 & $0.6 \%$ & $6.9 \%$ \\
3 & $1.6 \%$ & $11.1 \%$ \\
4 & $0.0 \%$ & $0.7 \%$ \\
5 & $1.8 \%$ & $22.6 \%$ \\
6 & $0.0 \%$ & $0.7 \%$ \\
7 & $0.5 \%$ & $3.8 \%$ \\
8 & $0.0 \%$ & $0.7 \%$ \\
9 & $0.8 \%$ & $2.8 \%$ \\
\hline
\end{tabular}

Correlating the recommended limits of AS/NZS 61000.3.2 from Table II and the typical operating current of $13.2 \mathrm{~A}$ suggests that the harmonics are above the recommended limits.

The significant current harmonics produced by the inverter fed unit included the $3^{\text {rd }}$ and $5^{\text {th }}$ at $6.6 \%$ and $4.3 \%$ of fundamental respectively. This correlates to significantly lower harmonic current emissions than the soft starter units when combined with the rated current, and well within the recommended limits. Steady state current for the inverter fed unit was $4.4 \mathrm{~A}$ during testing with a room temperature of $28^{\circ} \mathrm{C}$. 


\section{EFFECTS OF MULTIPLE UNITS}

DNSP customers will tend not to complain about power quality problems attributed to operation of their own equipment. Some power quality problems are also not immediately apparent to customers, such as harmonics. In most cases however, DNSP customers will notice voltage fluctuations due to their neighbour's air conditioning equipment. To assess the impact of having multiple air conditioner units on a single LV distributor, the data obtained in the laboratory tests, and specified penetration levels are utilised to determine the level of voltage fluctuations that might occur on a real system.

While the basis of the calculations are for evaluation on Australian distribution networks, these closely follow some network types in Europe and thus results are relevant to the wider international community.

The typical radial LV system considered for calculation of resulting voltage fluctuations consists of two overhead LV distributors, each of length 400m, as illustrated in Fig. 7.

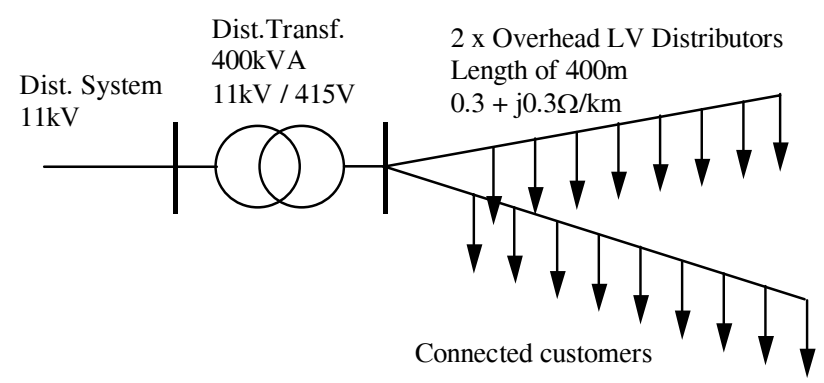

Fig. 7 - Typical radial LV system consisting of two LV Distributors

To complete the calculations the following is assumed:

(a) Flicker transfer upstream into MV distribution system from LV distributors is considered negligible due to the ratio of fault levels [8].

(b) Each residence with an air conditioner will have a soft starter type unit with starting characteristics as measured during the laboratory.

(c) The air conditioner units will start at a uniformly random time once every 20 mins.

(d) All residences and air conditioner units are distributed evenly along the LV distributors.

To incorporate the penetration levels a probabilistic approach is used to establish the number of air conditioner units on the LV distributor and the frequency of starting transients. In MATLAB the starting transient currents are used to calculate the resulting voltage fluctuations over a 10 minute period. From the 10 minute period the short term flicker perceptibility index, $\mathrm{P}_{\mathrm{st}}$, due to the voltage fluctuations is determined. A perceptibility index of unity indicates approximately $50 \%$ of the general population will be irritated by lamp flicker created by voltage fluctuations [7]. To determine the $\mathrm{P}_{\mathrm{st}}$ index the analytical technique described in AS/NZS 61000.3.3 using equations (1) and (2) is utilised.

$$
t_{f}=2.3\left(F \cdot d_{\text {max }}\right)^{3.2}
$$

$$
P_{s t}=\left(\Sigma t_{f} / T_{p}\right)^{1 / 3.2}
$$

where $t_{f}$ is the flicker impression time

$F$ is the shape factor of the voltage change $d_{\max }$ is the maximum relative voltage change $T_{p}$ is the total time interval (10 minutes)

A shape factor of $F=0.95$ is obtained for the respective front and tail times of the voltage change due to an air conditioner starting transient and Figure 7 of AS/NZS 61000.3.3. The maximum relative voltage change depends on the position of the air conditioner unit on the LV distributor, and is determined in the MATLAB simulation. A Monte Carlo approach is used to trial a number of different air conditioner starting times and location on the distributor. The resulting $95^{\text {th }}$ percentile $\mathrm{P}_{\text {st }}$ levels are presented in Table III.

Table III - Resulting $\mathrm{P}_{\mathrm{st}}$ levels at the end of the LV distributor for various

\begin{tabular}{|c|c|}
\hline \multicolumn{2}{|c|}{ penetrations of air conditioner units } \\
\hline $\begin{array}{c}\text { Air conditioner } \\
\text { penetration }\end{array}$ & $\begin{array}{c}\text { Resulting } 95^{\text {th }} \\
\text { percentile } \mathrm{P}_{\text {st }}\end{array}$ \\
\hline $40 \%$ & 0.67 \\
$60 \%$ & 0.73 \\
$80 \%$ & 0.74 \\
$100 \%$ & 0.78 \\
\hline
\end{tabular}

It is noted that the study overhead distributor is of lower impedance than some common types of overhead distributors, which may have as much as double the resistive impedance. It is also not uncommon in Australia to have LV distributors of much greater length.

The resulting flicker perceptibility indices presented in Table III suggest that there is limited headroom for other types of equipment, such as compressors, welders, etc. which may also appear in the LV network. This indicates that voltage fluctuations due to air conditioners could give rise to a number of customer complaints for DNSPs in the near future. It is noted that strengthening the LV network by reducing systems impedances may significantly reduce the magnitude of voltage changes. This may be achieved by DNSPs installing underground LV networks, and indeed is becoming more commonplace in new developments in Australia, albeit for aesthetic reason.

Compulsory installation of soft starters to DOL started sir conditioner units could also help to reduce voltage fluctuations. It is noted that recent improvement in soft starter technology will provide improved performance to the unit tested as part of this work. Endorsement of inverter fed air conditioner units may also assist in limiting power quality problems in the future.

\section{CONCLUSIONS}

Measurement of performance of current technology singlephase split-system air conditioners has been undertaken. Air conditioner units tested included three typical system configurations, direct on-line, soft starter, and inverter fed units. 
Starting current transients of the DOL and soft starter units do not comply with relevant standards with regards to the $6 \%$ voltage changed specified during starting. This is likely to cause significant voltage drop and customer complaints in LV distributors. This is expected as starting currents of up to $45 \mathrm{~A}$ maximum, of which both exceed, is usually accepted as the industry benchmark. Soft starters need further development but can easily be designed to provide more suitable performance. No significant steady state voltage drop problems were identified for the units tested. The net effect of high penetration of larger air conditioner units is increased levels of voltage fluctuations, leading to the possibility of increased customer complaints due to light flicker.

Harmonic emissions from the tested units are not anticipated as being of major concern. However, there are significant harmonics from asymmetrical soft starter current for short periods, and also due to saturation of the compressor motor during normal operation.

Inverter fed air conditioner units utilising three-phase motors provide the most suitable solution to power quality issues. Endorsement by utilities could assist in limiting power quality problems.

\section{REFERENCES}

[1] Australian Bureau Statistics, 2002, "www.abs.gov.au", Agency of the Australian Government, March 2002 Report.

[2] Integral Energy, 2004, "Internal study on the penetration of air conditioners", Confidential Integral Energy Report, September 2004.

[3] K. Tomiyama, J.P. Daniel, S. Ihara, 1998, "Modeling air conditioner load for power system studies", IEEE Trans. on Power Systems, vol. 13, no. 2, pp. 414-421.

[4] J.C. Hwang, 2001, "Assessment of air conditioner load management by load survey in Taipower", IEEE Trans. on Power Systems, vol. 16, no. 4, pp. 910-915.

[5] L. Moller, 2004, "Report on starting transients and steady state voltage and currents of direct online, soft starter and inverter type air conditioners", Integral Energy Power Quality and Reliability Centre, 9 March 2004.

[6] AS/NZS 61000.3.2, 2003, "Electromagnetic Compatibility (EMC) - Part 3.2: Limits - Limits for harmonic current emissions (equipment input current less than or equal to $16 \mathrm{~A}$ per phase)", Standards Australia, Table 1.

[7] AS/NZS 61000.3.3, 2003, "Electromagnetic compatibility (EMC) - Part 3.3: Limits - Limitation of voltage changes, voltage fluctuations and flicker in public low-voltage supply systems, for equipment with rated current less than or equal to 16A per phase and not subject to conditional connection", Standards Australia, Section 5.

[8] AS/NZS HB 264, 2003, "Power Quality Recommendations for the application of AS/NZS 61000.3.6 and AS/NZS 61000.3.7", Standards Australia, Section 4. 